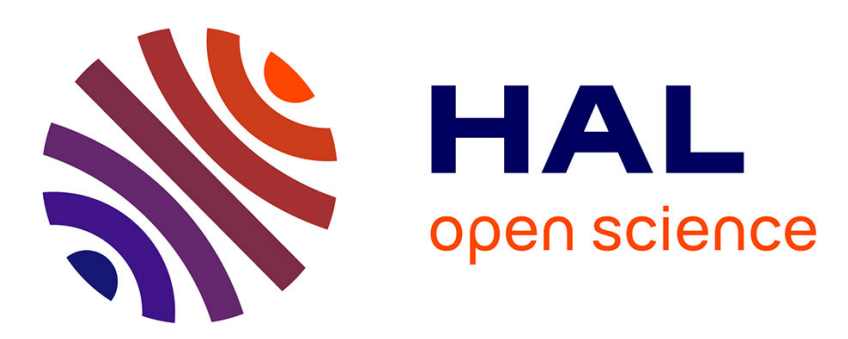

\title{
[MATH] precipitates in [MATH] Cu-based shape memory alloys : influence on the martensitic transformation and the thermal and pseudoelastic cycling
}

J. Pons, E. Cesari

\section{To cite this version:}

J. Pons, E. Cesari. [MATH] precipitates in $[\mathrm{MATH}] \mathrm{Cu}$-based shape memory alloys: influence on the martensitic transformation and the thermal and pseudoelastic cycling. Journal de Physique IV Proceedings, 1994, 04 (C3), pp.C3-151-C3-156. 10.1051/jp4:1994321 . jpa-00252518

\author{
HAL Id: jpa-00252518 \\ https://hal.science/jpa-00252518
}

Submitted on 1 Jan 1994

HAL is a multi-disciplinary open access archive for the deposit and dissemination of scientific research documents, whether they are published or not. The documents may come from teaching and research institutions in France or abroad, or from public or private research centers.
L'archive ouverte pluridisciplinaire HAL, est destinée au dépôt et à la diffusion de documents scientifiques de niveau recherche, publiés ou non, émanant des établissements d'enseignement et de recherche français ou étrangers, des laboratoires publics ou privés. 


\title{
$\gamma$ precipitates in $\beta$ Cu-based shape memory alloys: influence on the martensitic transformation and the thermal and pseudoelastic cycling
}

\author{
J. PONS ${ }^{(1)}$ and E. CESARI
}

Dept. de Fisica, Universitat de les Illes Balears, Ctra. de Valldemossa km 7.5, 07071 Palma de Mallorca, Spain

\begin{abstract}
The effect of different distributions of $\gamma$-phase precipitates on the martensitic transformation of $\beta \mathrm{Cu}-\mathrm{Zn}-\mathrm{Al}$ single crystals is reviewed. The changes of transformation temperatures brought about by the precipitates are related to the changes of the free energy terms included in the thermoelastic balance. In the same way, the evolution of the transformation in samples containing precipitates submitted to thermal and pseudoelastic cycling will be also discussed. In some cases, the presence of precipitates improves the behaviour of the material under cycling.
\end{abstract}

\section{INTRODUCTION}

The characteristics of martensitic transformations can be strongly influenced by the presence of secondphase precipitates inside the matrix. After the early studies of Rapacioli, Chandrasekaran and Lovey $[1,2]$ on the formation of $\gamma$ precipitates in the $\beta$ matrix of $C u$-Zn-Al shape memory alloys, further work has been devoted to the effect of such distributions of precipitates on the martensitic transformation $(\beta \leftrightarrow 18 \mathrm{R})$ of this alloy [3-5] as well as the behaviour under thermal [6,7] and pseudoelastic cycling [8]. The studies have been restricted to single crystals with an electron to atom ratio $\mathrm{e} / \mathrm{a}=1.48$. The present paper will review the main results.

Precipitates of the $\gamma$ phase can be produced in the $\beta$ phase matrix of $C u-Z n$-Al alloys by several heat treatments [1-5]. For example, the quench from temperatures in the range 670-970K (near the B2 ordering temperature) to temperatures lower than $320 \mathrm{~K}$ (but higher than $\mathrm{Ms}$ ) produces a distribution of small precipitates $(\sim 10 \mathrm{~nm}$ size $)$ coherent with the matrix. These precipitates, often called " $\gamma$-type" precipitates, are formed during the quenching under non-equilibrium conditions and their size and distribution depend on quenching characteristics. The majority of the particles are found to be cube shaped, the cube faces being parallel to the $(100)_{\beta}$ planes. After quenching, the electron diffraction patterns show inconmensurate spots coming from the precipitates, slightly displaced from the exact positions at $1 / 3$ distances between the fundamental $\beta$ reflections [2]. This incommensurate-like behaviour has been interpreted, after HREM studies, as produced by small domains $(\sim 5 \mathrm{~nm})$ fragmenting the precipitates [9]. The precipitates can be made to grow by additional short time ageings (flash heatings) at temperatures between 520 and $770 \mathrm{~K}$. After ageing, the electron diffraction patterns show commensurate positions as well as $\gamma$ superlattice reflections. The flash heating causes the precipitates to change gradually towards the equilibrium $\gamma \mathrm{Cu}-\mathrm{Zn}$ $A l$ (either by ordering or by incorporating $\mathrm{Al}$ ). The basic structure of the precipitates can be considered as very close to that of $\gamma \mathrm{Cu}-\mathrm{Zn}$, the presence of $\mathrm{Al}$ and boundary defects accounting for the differences [9]. When the first thermal treatment does not produce precipitates, such as a quench from the $\beta$ stability region $(\sim 1100 \mathrm{~K})$, the precipitates can as well be formed and made to grow by the additional flash heating. In this case, less dense distributions of precipitates are, generally, obtained.

When precipitates reach sizes bigger than $\sim 100 \mathrm{~nm}$ they lose the coherency with the matrix, being encircled by misfit dislocation loops with Burgers vectors of $<100\rangle_{\beta}$ type on the $\{100\}_{\beta}$ faces as well as $\left.<100\right\rangle_{\beta}$ and $1 / 2<111>_{\beta}$ vectors on the $\{110\}_{\beta}$ faces $[10,11]$.

(1) Now in post-doc stay at: Lab. Métallurgie Structurale, ENSCP, 11 rue Pierre et Marie Curie, 75231, Paris cedex 05, France 


\section{EXPERIMENTAL PROCEDURES}

We will give here some details concerning the alloys and their thermal treatments for which experimental results will be presented below.

The compositions of the single crytals grown by the Bridgman method, $\mathrm{Cu}-16.1 \% \mathrm{Al}-15.5 \% \mathrm{Zn}$ and $\mathrm{Cu}$ $16.3 \% A l-15.3 \% \mathrm{Zn}$ (at \%), corresponding to electronic concentration e/a $=1.48$, were mainly used. Their nominal transformation temperatures Ms are about $260-270 \mathrm{~K}$ and the B2 and L21 ordering temperatures are $\sim 820 \mathrm{~K}$ and $\sim 650 \mathrm{~K}$, respectively. Mainly two thermal treatments have been used, which are representative of the treatments generating $\gamma$ precipitates:

TTB: From the stability region of $\beta$ phase (1120K), air cooling to $770 \mathrm{~K}$ and, after $180 \mathrm{~s}$ at this temperature, quenching in ice-water.

TTD: After $15 \mathrm{~min}$ at $1120 \mathrm{~K}$ quenching into water at room temperature $(\sim 290 \mathrm{~K})$.

Subsequent flash heatings at $670 \mathrm{~K}$ for different times $\mathrm{t}^{*}$, followed by water quenching $(290 \mathrm{~K})$, produce distributions of $\gamma$ precipitates of variable densities and precipitate sizes, depending on the previous thermal treatment and time $t^{*}$. The results obtained for the thermal induced transformation in samples with precipitates have been compared with those corresponding to a reference thermal treatment (named TT1) which do not produce precipitates: air cooling from $1120 \mathrm{~K}$ to room temperature, and 24 hours aging at this temperature before the first transformation cycle.

The martensitic transformation of samples containing precipitates has been studied mainly by means of electric resistance measurements and calorimetry coupled with acoustic emission. In the present paper we will show results concerning the latter techniques. The high sensitivity calorimetric system, working at heating/cooling rates in the range $0.1-0.3 \mathrm{~K} / \mathrm{min}$ has been described elsewhere $[12,13]$. The results of microscopic observations will be presented as well.

\section{EFFECT ON TEMPERATURE-INDUCED TRANSFORMATIONS}

Concerning the transformation temperatures (figure 1), a different evolution with the time, $\mathrm{t}^{*}$, of flash heating is observed in the forward and reverse transformations. The temperatures Ms and Mf are progresively decreasing by increasing $t^{*}$ until $t^{*} \sim 100$ s, i.e. increasing the size of precipitates until $\sim 1 \mu \mathrm{m}$. Their values are always lower than the reference ones (TT1 treatment). The same behaviour is observed for As and Af for $\mathrm{t}^{*}<40 \mathrm{~s}$. Nevertheless, for longer flash heating times the reverse transformation is shifted to higher temperatures, even overcoming the reference ones. This evolution taking place in transformation temperatures results in significant increases of thermal hysteresis. Cycles shifted towards lower temperatures or including the reference one are obtained, in each case with larger area than the reference cycle. In the same way, the transformation ranges $\Delta \mathrm{M}=\mathrm{Ms}-\mathrm{Mf}$ and $\Delta \mathrm{A}=\mathrm{Af}-\mathrm{As}$ also increase. The behaviour is qualitatively the same regardless the thermal treatment prior to the flash heating being TTB or TTD. A noticeable diference shown by the samples subjected to TTD prior to flash heating is that the drastic increase of retransformation temperatures appears for somewhat higher $t^{*}$ values. By means of properly chosen experiments it has been verified that the decrease of transformation temperatures are not produced neither by changes in ordering during the flash heating nor by dislocations eventually produced when quenching back to room temperature. Values of transformation temperatures, heats exchanged and entropy changes for TTB and TTD samples with variable $t^{*}$ can be found in refs. [4,5].

Previous studies, monitoring the transformation by electrical resistance changes, have shown that for larger plateau times $\left(t^{*}=180 \mathrm{~s}\right)$ the whole transformation cycle is shifted towards higher temperatures and is considerably more tilted than the reference one (increase in $\Delta \mathrm{M}$ and $\Delta \mathrm{A}$ ). Such behaviour is explained by a larger amount of $\gamma$ phase in the matrix which induces noticeable changes in the $\beta$ composition (becoming poorer in $A l$ content), shifting the equilibrium temperature to higher values and creating concentration gradients in the matrix, which increase $\Delta \mathrm{M}$ and $\Delta \mathrm{A}[3]$.

Restricting our discussion to $t^{*}$ values up to $100 \mathrm{~s}$, we can distinguish two main situations, corresponding to $t^{*}<40 \mathrm{~s}$ and $t^{*} \geq 40 \mathrm{~s}$. For short flash heating times, the elastic contributions to the thermoelastic balance $[14,15]$ take increasing values with $t^{*}$, reaching values of $40-60 \mathrm{~J} / \mathrm{mol}(2-3$ times the reference ones) $[4,5]$. Optical and transmission electron microscopy observations have shown that in this situation the precipitates (up to $\sim 0.4 \mu \mathrm{m}$ ) are completely absorbed by martensite plates (figure $2 \mathrm{a}$ ). It is known that the shape deformation associated to the $\beta \leftrightarrow 18 \mathrm{R}$ transformation results in a change of the interplanar distance between the $\{100\}$ planes of the $\beta$ phase: one distance becomes shorter by about $10 \%$, another increases by $10 \%$ 


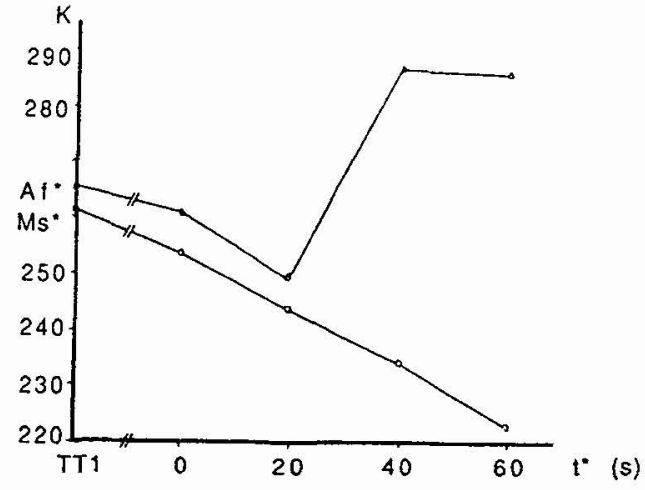

Figure 1. Plot of Ms and Af as a function of t* for samples submited to TTB and flash heating to $670 \mathrm{~K}$ (from ref. 4 ) while the third remains almost unchanged [16]. For cuboidal precipitates with $\{100\}_{\beta}$ habit plane, the cubic hole in the matrix where the precipitate is embedded has to be changed, due to the transformation, into an orthorombic shape. Due to this shape change a large amount of elastic accommodation is needed. In fact, the presence of precipitates increases the elastic energy about $20 \mathrm{~J} / \mathrm{mol}$ [4-5], which is consistent with the "extra driving force" $\Delta \mathrm{Ms}$ $\Delta \mathrm{s}$, with $\Delta \mathrm{Ms} \sim 15 \mathrm{~K}$ and $\Delta s \sim 1.2 \mathrm{~J} / \mathrm{molK}$. This elastic energy is essentially recovered through the reverse transformation since the cubic shape is also recovered (however, as it will be commented below, partial relaxation occurs around the precipitates). Thus the elastic interaction provides an important contribution for the decrease of the whole transformation range [17].

Larger precipitates (produced after flash heating for $t^{*}>40 \mathrm{~s}$ ) are more difficult to be absorbed by a single martensite plate. In this case the transformation proceeds by the formation of smaller plates between precipitates with the usual self-accommodating character but with much smaller sizes, depending on the precipitate distribution density. Near the precipitates the self-accommodation is difficult and complex arrangements of very small plates are produced (figure $2 \mathrm{~b}$ ). This behaviour accounts for the decrease observed in the elastic term, as well as for the important increase in the friction (hysteresis width) [17-18]. In this case, the hysteresis does not depend directly on the size of precipitates, as does the decrease of $\mathrm{Ms}$ observed for $t^{*}<40 \mathrm{~s}$ do, but depends on the distribution density, i.e., the distance between precipitates, which restrict the martensite plate size.
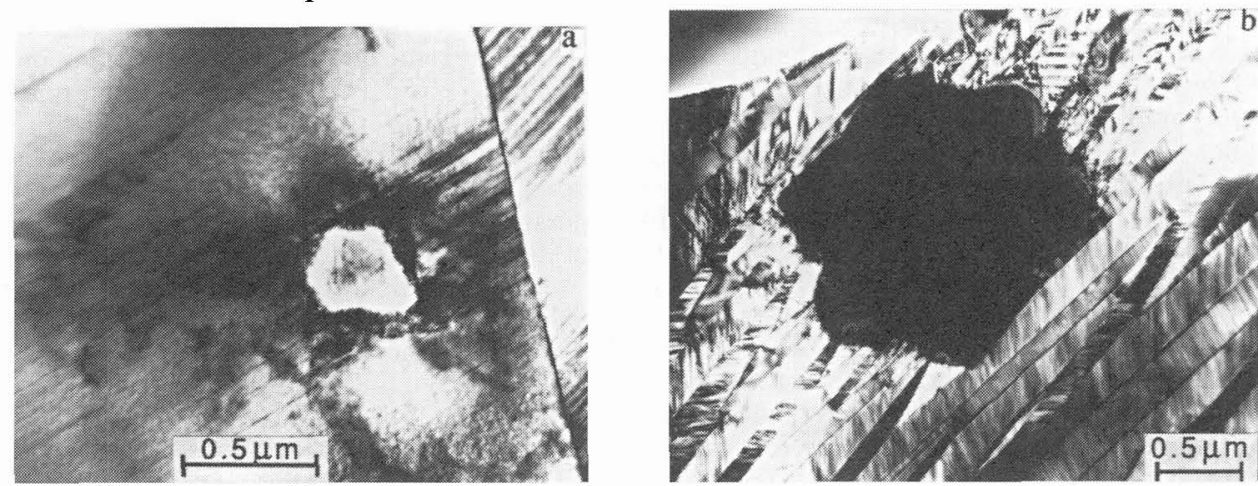

Figure 2. Image of precipitates in a sample with nominal Ms of $\sim 320 \mathrm{~K}$, observed at room temperature (martensite state). a) TTD/10s; b) TTD/80s

\section{THERMAL CYCLING}

The successive thermal or mechanical cycling through a martensitic transformation, even of thermoelastic character, introduces defects in the material and affects the transformation characteristics. In $\mathrm{Cu}-\mathrm{Zn}-\mathrm{Al}$ shape memory alloys (with no precipitates) the effects of thermal cycling on the martensitic transformation have been analysed by several authors [19-24]. Some particular effects have been found when considering thermal cycling in samples with $\gamma$ precipitates. They are interesting not only because the transformation mechanisms can be better understood, when comparing with precipitate-free samples, but also because in some cases the behaviour of the material under thermal cycling is clearly improved, which is important for practical applications.

In order to summarize the main features we will show the results obtained by calorimetry and microscopy in samples with $T T B / t^{*}=20 \mathrm{~s}$ and TTD $/ t^{*}=60$ s (mean size of precipitates of $60 \mathrm{~nm}$ and $300 \mathrm{~nm}$, respectively), thermally cycled up to 300 cycles. They are representative of the different behaviours of samples containing 
dense distributions of small precipitates (case $\mathrm{TTB} / 20 \mathrm{~s}$ ) and distributions of bigger precipitates (case TTD/60s). The hysteresis cycles and their evolution are presented in figure 3 . As it can be seen, in the first case the macroscopic characteristics of the transformation are practically unaltered by cycling. Only a relatively small smoothing of the thermograms and a reduction of the values of $Q$ (heat exchanged) and $\Delta s$, mainly related to retained martensite (which also occurs in precipitate-free samples cycling) are noticed. Conversely, the specimens containing bigger precipitates show a marked evolution of the transformation temperatures during cycling, specially the Ms and Mf, shifting the transformation cycle to higher temperatures and reducing its hysteresis, thus approaching the reference thermal treatment behaviour $[6,7]$.


Figure 3. Hysteresis cycles corresponding to different stages of cycling for the samples submitted to: a) TTB, $t^{*}=20 \mathrm{~s}$, cycles 1 and $300 ;$ b) TTD, $t^{*}=60 \mathrm{~s}$, cycles 1,150 and 300 (from ref. 6 ).

TEM observations have been performed from cycled bulk samples, at different stages of cycling, in order to follow the generation of dislocations [7] and to compare with corresponding precipitate-free samples, which were previously studied [24]. Dislocations of mixed type, mainly with $\mathbf{b}=<100>\beta$ and $\mathbf{u}=<111>\beta$ are formed in the matrix between the precipitates. These dislocations are of the same type as those formed in samples without precipitates, although the distributions observed in samples containing precipitates have always lower densities, specially in the cases of big precipitates. It must be remembered that martensite plates are smaller in samples with precipitates, being also this difference more marked as bigger the precipitates are (the plates can not overcome the precipitates). These facts confirm the relationship between the martensite plate size and the formation of dislocations in the impingements of martensite plates, discussed in $[7,18,24]$. Dislocations also appear in the matrix surrounding the precipitates [7]. Small dislocation segments connecting the matrix with the faces of initially coherent precipitates are already visible after the first stages of cycling (up to 50 cycles). Bigger and denser dislocation arrays are formed in the vicinity of initially non-coherent precipitates (see figure 4). The formation of these dislocations reveal a non-completely elastic accommodation of the intrinsic deformation associated to the martensitic transformation commented above. Nevertheless, once formed, the main role of these dislocations is to facilitate the martensite-precipitate accomodation, thus reducing the elastic energy involved in the transformation, as it has been confirmed from calorimetric measurements. This effect is more pronounced in the specimens containing bigger precipitates.
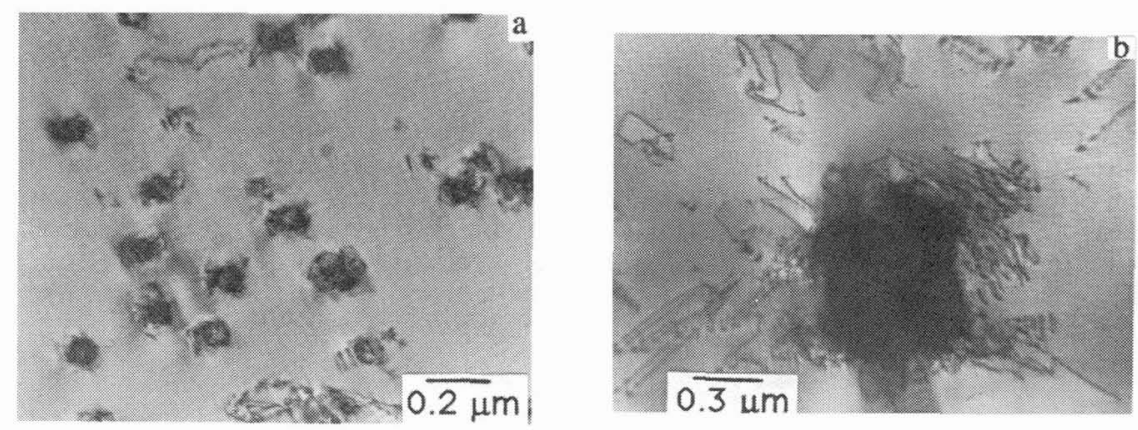

Figure 4. Dislocations formed around the precipitates after 10 thermal cycles. a) TTB, $t^{*}=20 \mathrm{~s}$; b) TTD, $t^{*}=60 \mathrm{~s}$ (from ref. 7). 
The role played by both kinds of dislocations is different. In the first case, being the dislocations observed in the matrix between precipitates equivalent to those observed in the matrix of precipitate-free specimens, it can be can assumed that, in a first approximation, they bring about the same effects. These effects mainly consist of a sligth decrease of the whole transformation cycle to lower temperatures $(\sim 5 \mathrm{~K}$ for $200-300$ cycles) and a few degrees increase of hysteresis [23,24]. On the other hand, as mentioned above, the dislocations around the precipitates reduce the energy for the accommodation of the martensite in the following cycles and, then, reduce as well the overcooling needed in the first cycles, thus increasing the transformation temperatures. In the case of dense and small precipitates, the effect of the dislocations in the matrix is compensated by the reduction in martensite-precipitate accomodation energy, thus leading to a high stability of the transformation during cycling. When big precipitates are present the latter term is clearly dominating, which is reflected in the experimentaly observed evolution of transformation temperatures.

\section{STRESS-INDUCED TRANSFORMATIONS. PSEUDOELASTIC CYCLING}

Pseudoelastic cycling through the martensitic transformation, induced by tensile stress at constant temperature, has been the subject of several studies in $C u-Z n-A l$ with no precipitates, concerning specially the fatigue behaviour [25-27]. Additional interest in pseudoelastic cycling is related to the fact that it is one of the available methods to induce the two way shape memory effect (TWSME) [28].We will concentrate on the effects of $\gamma$ precipitates on the stress-strain curves and their evolution, as well as on the induction of the TWSME by pseudoelastic cycling in tension.

The transformation cycle $(\sigma-\varepsilon)$ is modified by pseudoelastic cycling. In precipitate-free single crystals a decrease of $\sigma_{c}$ (critical stress to start the transformation) and an increase of the stress necessary to complete the transformation (transformation hardening) is observed [25]. Both effects lead to an increased slope of the curves, being the hysteresis also increased (by a factor $\sim 2$ ). In samples with dense distributions of small precipitates $(\sim 100 \mathrm{~nm})$, obtained after a TTB treatment, the loading path gradually shifts to lower stresses during the first stages of cycling, heavily reducing the hysteresis width (figure 5). This evolution is qualitatively equivalent to that found after thermal cycling in samples containing big precipitates, as described above. After a more prolongued cycling, the start of the transformation (end of retransformation) is progressively shifted to lower stresses, thus tilting the $\sigma-\varepsilon$ curves, but, at difference with precipitate-free material, no increase of stress is observed at the end of transformation (start of retransformation), i.e. no net hardening is produced.

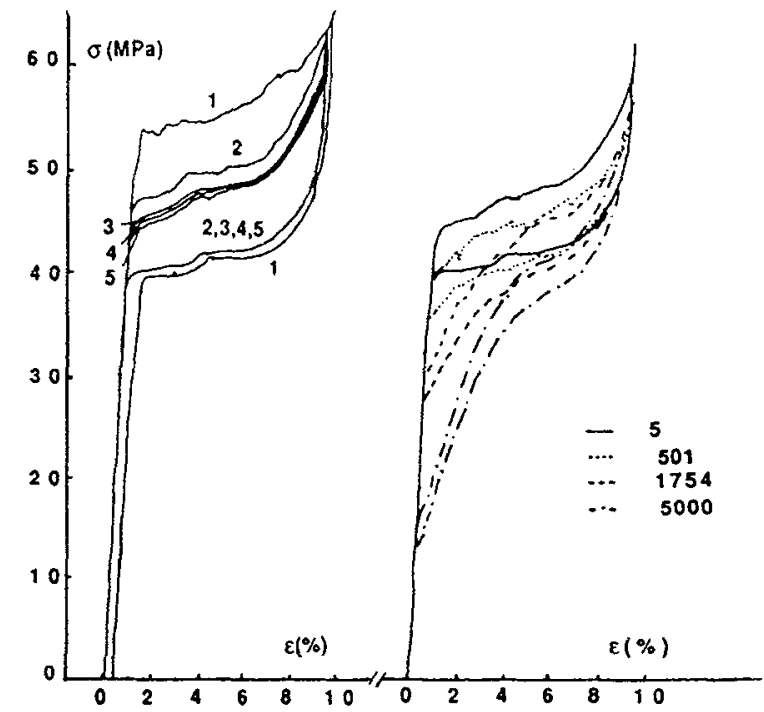

Figure 5. Stress-strain curves corresponding to several stages of pseudoelastic cycling for a sample submitted to TTB.
TEM observations of pseudoelastically cycled precipitate-free specimens showed the presence of dislocations in the $\beta$ matrix $(\mathbf{b}=<100>\beta, \mathbf{u}=<111>\beta)$ arranged in bands [29]. In the samples containing precipitates, such bands have also been observed, but in smaller amounts and after more prolongued cycling. As an example, in a sample without precipitates cycled until 1500 cycles it was estimated an average distance between bands of $370 \mu \mathrm{m}$, while nearly no bands were observed in a specimen with precipitates cycled in an identical way [8]. Dislocation loops around the precipitates were also observed after cycling (figure 6). The Burgers vectors of the loops are parallel to the $[010]_{18 \mathrm{R}}$ direction of the induced martensite variant. These loops, formed after the first cycles, facilitate the accomodation of the stress-induced variant of martensite in the following cycles, lowering the accomodation energy for this variant and, then, the transformation stress.

This fact brings about a "selection" of this variant, which is manifested by the presence of the TWSME. Indeed, in samples containing precipitates, the TWSME has been observed after a few hundreds of cycles 




(one order of magnitude lesser number of cycles than in precipitate-free material [30]), when the dislocation bands in the matrix (which are responsible of the TWSME in the specimens without precipitates) are still not formed. The facility of the induction of the TWSME and the better stability of transformation temperatures during thermal cycling in samples with precipitates are attractive results regarding the applications of these materials.

Figure 6. Dislocation loops around the precipitates observed after pseudoelastic cycling (from ref. 8).

\section{ACKNOWLEDGEMENTS}

J.P. acknowledges the DGICyT of Spain the concession of a post-doctoral grant of the MEC-MRT program. Partial finantial support from the DGICyT (project num. PB90-0039) is gratefully acknowledged.

\section{REFERENCES}

1/ R. Rapacioli, M. Chandrasekaran and F.C. Lovey: Proc. Int. Conf. on Soli-Solid Phase Transformations (Pittsburg, PA, USA), H.I. Aaronson, D.E. Laughlin, R.F. Sekerka and C.M. Wayman eds., Metallurgical Soc. of AIME, 1981, p. 739

2/ F.C. Lovey, R. Rapacioli and M. Chandrasekaran; phys. stat. sol. (a) 68 (1981) K105

3/ R. Rapacioli and M. Chandrasekaran: Proc. Int. Conf. on Martensitic Transformations (Cambridge, MA, USA), MIT Press, 1979 , p. 596

4/ C. Auguet, E. Cesari, R. Rapacioli and Ll. Mañosa: Scripta Metall. 23 (1989) 579

5/ J. Pons and E. Cesari: Thermochim. Acta 145 (1989) 237

6/ J. Pons, E. Cesari and M. Roca: Mat. Letters 9 (1990) 542

7/ J. Pons and E. Cesari: Acta Metall. Mater. 41 (1993) in press

$8 /$ J. Pons, M. Sade, F.C. Lovey and E. Cesari: Proc. Int. Conf. on Martensitic Transformations (Monterey, CA, USA), 1992 , in press.

9/ F.C. Lovey, G. Van Tendeloo, J. Van Landuyt, M. Chandrasekaran and S. Amelinckx: Acta metall. 32 (1984) 879

$10 /$ F. C. Lovey and E. Cesari: Mat. Sci. and Eng. A129 (1990) 127

11/ M. Chandrasekaran, J. Pons and E. Cesari: Proc. 10th European Congress on Electron Microscopy (Granada, Spain),

Vol. II, A. Lopez-Galindo, M.I. Rodriguez-Garcia Eds. (1992) p. 241

12/ C. Picornell, C. Seguí, V. Torra, C. Auguet, Ll. Mañosa, E. Cesari and R. Rapacioli: Thermochim. Acta 106 (1986) 209

13/ G. Guénin, J.L. Macqueron, M. Mantel, C. Auguet, E. Cesari, Ll. Mañosa, A. Planes, J. Ortín, C. Picornell, C. Seguí and V. Torra: Proc. Int. Conf. on Martensitic Transformations (Nara, Japan), I. Tamura ed., The Japan Inst. of Metals, 1986, p. 794

14/ L. Delaey, R.V. Krishnan, H. Tas and H. Warlimont: J. of Mat. Sci. 9 (1974) 1545

15/ J. Ortin and A. Planes: Acta Metall. 36 (1988) 1873

16/ M. Sade, A. Hazarabedian, A. Uribarri and F.C. Lovey: Proc. Int. Conf. on Phase Transformations (Cambridge, UK),

G.W. Lorimer ed., The Institute of Metals, 1987, p. 279

17/ F. C. Lovey, E. Cesari, C. Auguet, L1. Mañosa and R. Rapacioli: Mat. Sci. Forum 56-58 (1990) 493

18/ J. Pons: Thesis, Dept. Física, Univ. Illes Balears, 1992

19/ S. Kajiwara and T. Kikuchi: Acta Met. 30 (1982) 589

20/ J. Ilczuk and H. Morawiec: phys. stat. sol. (a) 97 (1986) 371

21/ J. Perkins and W.E. Muesing: Metall. Trans. A14 (1983)33

22/ J. Perkins and P. Bobowiec: Metall. Trans. A17 (1986) 195

23/ C. Auguet, E. Cesari and Li. Mañosa: J. Phys. D: Appl. Phys. 22 (1989) 1712

24/ J. Pons, F.C. Lovey and E. Cesari: Acta Metall. Mater. 38 (1990) 2733

25/ M. Sade, R. Rapacioli and M. Ahlers: Acta Met. 33 (1985) 487

26/ L. Delaey, J. Janssen, D. van de Mosselaer, G. Dullenkopf and A. Deruyttere: Scripta Met. 12 (1978) 373

27 J. Janssen, F. Willems, B. Verelst, J. Maertens and L. Delaey: J. de Physique 43 (1982) C4-809

28/ T.A. Schroeder and C.M. Wayman: Scripta Met. 11 (1977) 225

29/ M. Sade, A. Uribarri and F.C. Lovey: Phil. Mag. A 55 (1987) 445

30/ E. Cesari, C. Picornell, J. Pons and M. Sade: J. de Physique 1 (1991) C4-451 